\title{
Estudo de espécies de pescado potencialmente aproveitáveis na cadeia produtiva do litoral sul do Estado do Rio de Janeiro
}

\section{Study of potentially usable species in the production chain of the south coast of the State of Rio de Janeiro}

\author{
Amanda Lima Albuquerque Jamas ${ }^{* 1}$, Pedro Paulo de Oliveira Silva ${ }^{2}$, Juliana Domingues dos Santos Carvalho ${ }^{3}$, Elizete \\ Amorim $^{4}$, Gesilene Mendonça de Oliveira ${ }^{5}$
}

\begin{abstract}
Resumo: No Rio de Janeiro, a produção de pescado ocorre de maneira ampla em contingente de espécies, porém, algumas se encontram em situação de sobrepesca, tornando-se importante o estudo de espécies potencialmente aproveitáveis do ponto de vista nutricional, tendo em vista o alto volume de desembarque e a baixa exploração econômica que estas oferecem no Estado. Com isso, a identificação e caracterização de novas fontes de aproveitamento do pescado para maior incorporação na cadeia produtiva, possibilita a obtenção de um produto de maior valor agregado. Este trabalho tem por objetivo fomentar o potencial que as principais espécies de bagre desembarcadas, Cathorops spixii (Agassiz, 1829) e Genidens barbus (Lapècede, 1803), oferecem na cadeia produtiva de pescado na região conhecida como Costa Verde, litoral sul do Rio de Janeiro, pois o bagre foi uma das dez espécies mais desembarcadas em nível nacional em 2010, e de baixo aproveitamento no mercado consumidor. Na Baía de Sepetiba no Município de Itaguaí, RJ, em determinadas épocas do ano estas espécies apresentam certa demanda e boa aceitabilidade pelo mercado consumidor local sob a forma salgada e/ou seca. Neste contexto, esta revisão tem como proposta evidenciar o potencial nutritivo e tecnológico que as espécies supracitadas apresentam para a produção de um produto com valor agregado, para estimular consumo e renda, além de fornecer a sustentabilidade do processo e da cadeia produtiva do pescado na diversificação de produtos no litoral sul do estado do Rio de Janeiro.
\end{abstract}

Palavras-chaves: valor agregado, sustentabilidade, Genidens barbus, Cathorops spixii

\begin{abstract}
In Rio de Janeiro, fish production occurs widely in number of species, but some are in overfishing, making it important to study potentially exploitable species from a nutritional point of view, considering the high volume landing and low economic exploitation they offer in Estado. Thus, the identification and characterization of new sources of fish exploitation for greater incorporation in the production chain, enables obtaining of a higher value-added product. This work aims to encourage the potential that the main species of catfish landed Cathorops spixii (Agassiz, 1829) and Genidens barbus (Lapècede, 1803) offers in the production of fish sector in the municipality of Itaguai, Rio de Janeiro, as these species are among the most landed in Sepetiba Bay, and low use made in the consumer market. Considering that, at certain times of the year these species have certain demand and good acceptance by the market in this region under the salted and dried fish form, this work aims to study the obtaining of a higher value-added product as an alternative to stimulate consumption and income, and through the sustainability of the process to ensure a diversified product, healthy and safe for the consumer.
\end{abstract}

Key words: value added fish, sustainability, Genidens barbus, Cathorops spixii

\footnotetext{
*Autor para correspondência

Recebido para publicação em 20/06/2015; aprovado em 10/11/2015

${ }^{1}$ Instituto de Tecnologia de Alimentos, UFRRJ.Rodovia BR 465, km 7, Seropédica - RJ. CEP: 23.890-000. E-mail: amanda.jamas@ yahoo.com.br

${ }^{2}$ Departamento de Tecnologia de Alimentos, UFRRJ. Rodovia BR 465, km 7, Seropédica - RJ. CEP: 23.890-000. E-mail: ppos@ufrrj.br

${ }^{3}$ Instituto de Tecnologia de Alimentos, UFRRJ. Rodovia BR 465, km 7, Seropédica - RJ. CEP: 23.890-000. E-mail: julianads.carvalho@ gmail.com

${ }^{4}$ Departamento de Tecnologia de Alimentos, UFRRJ.Rodovia BR 465, km 7, Seropédica - RJ. CEP: 23.890-000. E-mail:amorizete@ ufrrj.br

${ }^{5}$ Departamento de Tecnologia de Alimentos, UFRRJ. Rodovia BR 465, km 7, Seropédica - RJ. CEP: 23.890-000. E-mail: gesilene@ufrrj.br
} 


\section{INTRODUÇÃO}

O pescado é um dos alimentos mais completos do ponto de vista nutricional. Isto ocorre em função da presença de proteínas de alto valor biológico, alta digestibilidade, baixo colesterol e quantidades significativas de vitaminas hidrossolúveis, como as do complexo B e as lipossolúveis, principalmente as vitaminas A, D e E (NUNES et al., 2008).

De acordo com dados da Organização das Nações Unidas para Agricultura e Alimentação (FAO), o pescado representa uma importante fonte de proteína animal, uma vez que uma porção de $150 \mathrm{~g}$ de peixe fornece cerca de 50 a $60 \%$ das necessidades diárias de proteínas para um adulto. A proteína do pescado contribui com cerca de $17 \%$ do consumo da população mundial e $6,5 \%$ de toda a proteína consumida pelo homem (FAO, 2014). Portanto, observa- se que o mercado para alimentos é extremamente competitivo, visto que inúmeras são as ofertas de boas fontes proteicas, sendo necessária agregação de valor ao pescado a fim de inseri-lo no mercado de forma diversificada e sólida. Os incentivos ao consumo de pescado devem ser estimulados a fim de aumentar o consumo per capita ano, além da sua acessibilidade a populações carentes.

O mercado para pescados apresenta algumas particularidades que influenciam nos níveis de consumo da população, estes relacionados à sua perecibilidade, sazonalidade da oferta e flutuações nos preços. Porém, peixes de menor preço podem substituir nutricionalmente os de maior preço, pois o que torna o preço elevado não é o valor nutricional e sim as suas características organolépticas, a quantidade capturada de acordo com sua maior ou menor exploração ou importância econômica, demanda no mercado e tradição cultural e gastronômica (GONÇALVES, 2011).

Espécies potencialmente aproveitáveis são aquelas que normalmente aparecem nas estatísticas de desembarque, cujas capturas oferecem o descarte ou baixo valor no mercado, e o aproveitamento destas será variável em cada região. A aparência geral, odor, sabor, cor e textura também serão determinantes na aceitação do produto pelo consumidor, e dessa forma os peixes são classificados em quatro grupos básicos: peixes de primeira linha (como badejo, cherne, linguado, robalo, merluza, namorado); segunda linha (atum, dourado, garoupa, mero, marlim, pargo, trilha, pescada, anchova); terceira linha (corvina, bonito, cação, tainha, vermelho sororoca) e peixes de quarta linha, no qual o bagre se inclui, dentre outros como baiacu, parati, sardinha (OETTERER, 2002; GONÇALVES, 2011).

Reis (1986) identificou os bagres marinhos como o segundo grupo mais abundante de peixes, contribuindo com $25 \%$ das capturas das pescarias artesanais. Estes por sua vez são distribuídos ao longo da costa brasileira, apresentando relevância na economia enquanto recurso pesqueiro desde Colômbia, principalmente Letícia, até Alagoas, além da região Sul do país. Porém, na região Sudeste é um recurso pouco explorado economicamente, mas que possui um forte potencial de inserção no mercado visto a sua abundância nesta região. Além disso, o bagre possui propriedades nutricionais semelhantes a algumas espécies de importância econômica que encontram-se em estado de sobrepesca.

No Rio de Janeiro, a Baía de Sepetiba é uma importante área em que se identificam variedades de muitas espécies sendo a Família Ariidae uma das mais abundantes nas capturas por redes de arrasto de fundo, e Genidens (Netuma) barbus (Lacépede, 1803) e Cathorops (Arius) spixii (Agassiz, 1829) estão entre as cinco espécies da Família Ariidae registradas nesta Baía além das espécies Genidens genidens (Valenciennes, 1839), Sciadeichthys luniscutis (Valenciennes, 1840) e Bagre marinus (Mitchill, 1814) (AZEVEDO et al., 1998; ARAÚJO et al., 1998).

Neste contexto, objetivou-se evidenciar o potencial de explotação sustentável das espécies de Bagre Cathorops spixii (Agassiz, 1829) e Genidens barbus (Lapècede, 1803) no litoral sul do Rio de Janeiro e demonstrar o valor nutricional e tecnológico desta matéria-prima para a região de Costa Verde, litoral sul do estado do Rio de Janeiro, a partir da implementação de métodos tradicionais como o de salga de peixes, e a transferência de tecnologias sociais, como o emprego da secagem com a utilização de energia renovável para agregação de valor ao produto, maior rentabilidade aos pescadores artesanais e o fortalecimento da cadeia produtiva de pesca na região.

\section{MORFOLOGIA, BIOLOGIA ALIMENTAR E REPRODUTIVA DAS ESPÉCIES DE BAGRE}

Pertencentes à Família Ariidae, os bagres marinhos podem possuir porte médio a grande, e como características morfológicas específicas apresentam dorso cinza a marromescuro, ventre branco a amarelado, cabeça com perfil dorsal reto, pares de barbilhões nos maxilares, orifícios nasais próximos entre si, placas de dentes relacionadas ao vômer, nadadeiras peitorais com espinhos serrilhados, nadadeira caudal furcada. As placas de dentes relacionadas ao vômer são comumente utilizadas para diagnose dos gêneros, facilitando a caracterização da espécie (MARCENIUK, 2005).

Figura 1. Bagre (Genidens barbus) capturado na Baía de Sepetiba, RJ

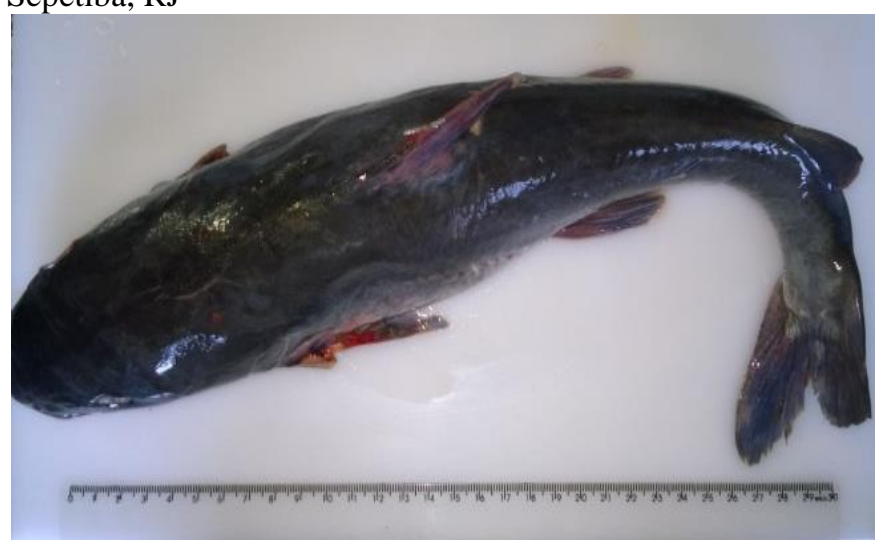

A alimentação dos peixes na natureza varia conforme o seu desenvolvimento para a adaptação ao meio, sendo assim, menor será o grau de competitividade por alimento, e suas necessidades fisiológicas serão supridas quando houver a migração, maturação e reprodução sexual (ZAVALACAMIN, 1996). A análise do conteúdo estomacal pode fornecer informações sobre o tipo de alimentação e o nicho ecológico apresentado pela espécie (MENDES; BARTHEM, 2010). Genidens barbus e Cathorops spixii possuem hábitos alimentares zoófagos (GUEDES; VASCONCELOS,1980), sendo os poliquetas presentes em mais de $80 \%$ do alimento ingerido, portanto estas estarão inseridas de forma relevante 
na cadeia alimentar destas espécies (AMARAL; MIGOTTO, 1980).

As espécies de Bagre têm como local de alimentação, abrigo e reprodução e no período de desova se deslocam para a desembocadura de rios e regiões lagunares, pois estas águas possuem baixas salinidades, e devido ao fato dos seus ovócitos serem grandes, altas salinidades comprometem a sua viabilidade por causar desidratação (HOSTIM-SILVA, 2009). A espécie Cathorops spixii apresenta um desenvolvimento ovocitário sincrônico caracterizado por apresentar dois lotes de ovócitos dentro dos ovários, ovócitos de reserva e ovócitos vitelo gênicos que virão a se maturar e serão liberados no período de desova (VAZZOLER, 1996). No momento em que se efetiva o completo desenvolvimento desses ovócitos, estes são incubados sob a cavidade bucal dos pais, conferindo proteção contra a predação, interferentes químicos ou físicos da água, como a salinidade e temperatura, possibilitando a migração para outros locais e garantindo maior sobrevivência de sua prole (HOSTIM-SILVA et al., 2009).

A desova ocorre nos meses de novembro a janeiro, meses nos quais coincidem com temperaturas mais altas, estas importantes para o desenvolvimento embrionário, porém este pode ocorrer em épocas diferentes como um mecanismo de evitar competições entre as espécies e possibilitar a sobrevivência de peixes jovens (GOMES et al., 1999). O bagre Genidens barbus se reproduz nos meses de agosto a setembro no estuário da Lagoa dos Patos, a maturação sexual ocorre de acordo com o deslocamento para o interior da lagoa e promovem a desova entre o fim da primavera e início do verão, retornando ao mar ao se tornarem adultos, após os primeiros anos de vida (ARAÚJO, 1983).

\section{OCORRÊNCIA DE BAGRES E SUA IMPORTÂNCIA NA PESCA EXTRATIVA NACIONAL E NO ESTADO DO RIO DE JANEIRO}

Dentro das diversas espécies de bagres marinhos, o bagre-branco (Genidens barbus) e bagre-amarelo (Cathorops spixii) se assemelham quanto aos aspectos de sua biologia alimentar e reprodutiva, porém alguns parâmetros como: áreas de seus habitats (localização e profundidade) concentrações de salinidade, além da pluviosidade, temperatura e transparência das águas se apresentam de forma particular para cada espécie (QUEIROZ et al., 2006). As espécies Cathorops spixii ocorrem em amplas variações de salinidade e áreas de profundidade, exceto no momento da desova que esta salinidade busca a ser baixa para que haja a proteção dos ovos (HOSTIM-SILVA, 2009). Em contrapartida, formas juvenis de Genidens barbus são encontradas em salinidades mais elevada, fato este relacionado à presença dos adultos em alto mar (MISHIMA; TANJI, 1983). Além disso, esta espécie possui maior tolerância às demais variações ambientais como a pluviosidade, temperatura e transparência da água quando comparados a Cathorops spixii. Estes mecanismos tem por finalidade evitar a competitividade interespecífica (GOMES; ARAÚJO, 2004).

No litoral brasileiro é relatada a ocorrência de 8 gêneros e 21 espécies, e para a região sudeste, 7 gêneros e 10 espécies (Aspistor luniscutis, Bagre bagre, B. marinus, Cathorops spixii, Genidens barbus, G. genidens, G. machadoi, Hexanematichthys parkeli, Notarius grandicassis e Potamariusgrandoculis) (FIGUEIREDO; MENEZES, 1978;
MENEZES et al., 2003). As espécies Cathorops spixii e Genidens barbus conhecidos vulgarmente como bagreamarelo e bagre-branco, respectivamente, ocorrem comumente nas regiões costeiras, estuários e rios costeiros na América do Sul, sendo que G. barbus podem ocorrer em plataformas continentais com até $40 \mathrm{~m}$ de profundidade, e estas espécies podem atingir comprimento máximo de aproximadamente $300 \mathrm{~mm}$ e $1200 \mathrm{~mm}$, respectivamente (MARCENIUK, 2005).

O bagre representa uma das onze espécies mais capturadas no Brasil em 2010, e estas representaram mais da metade $(50,7 \%)$ do total de peixes marinhos capturados no país (BRASIL, 2010). A produção de Bagres oriunda da pesca extrativa, aquicultura continental e a produção nacional oriunda destas nos anos de 2009, 2010 e 2011, estão descritas nas Tabelas 1 e 2 .

Tabela 1. Produção de bagres e a produção nacional oriunda da pesca extrativa, expressa em toneladas, nos anos de 2009, 2010 e 2011

\begin{tabular}{lcc}
\hline Ano & Pesca extrativa de Bagres $(\mathrm{t})$ & Produção nacional $(\mathrm{t})$ \\
\hline 2009 & $10.108,8$ & $585.671,5$ \\
2010 & $9.554,5$ & $536.454,9$ \\
2011 & $9.636,9$ & 553.670 \\
\hline
\end{tabular}

Fonte: Brasil, 2011.

Tabela 2. Produção de bagres e produção nacional oriunda da aquicultura continental, expressa em toneladas, nos anos de 2009, 2010 e 2011

\begin{tabular}{lcc}
\hline Ano & $\begin{array}{c}\text { Aquicultura Continental de } \\
\text { Bagres }(\mathrm{t})\end{array}$ & Produção nacional (t) \\
\hline 2009 & $3.484,1$ & $337.353,0$ \\
2010 & $4.073,4$ & $394.340,0$ \\
2011 & $7.048,1$ & $544.490,1$ \\
\hline
\end{tabular}

Fonte: Brasil, 2011.

As espécies Cathorops spixii e Genidens barbus ocorrem ao longo da costa brasileira e são descritas por diversos autores (AZEVEDO et al, 1998; MARCENIUK, 2005; SANTANA et al., 2007; SCHMIDT et al., 2008). O bagrebranco (Genidens barbus) foi descrito por Martins (2013) como a espécie mais capturada na Baía de Tijucas (RS), onde representou $53 \%$ do peso total desembarcado, sendo também encontrada como uma das espécies mais abundantes dentre as espécies de bagre que ocorrem na Lagoa de Patos, RS. (ARAÚJO, 1983). No litoral sul de São Paulo, o segmento que atua na captura de G. barbus é o artesanal, e este representa $95 \%$ dos produtos desembarcados (MENDONÇA, 2008).

Na Baía de Sepetiba (RJ), a predominância de bagres em áreas estuarinas em arrastos de fundo contribuiu com $28,5 \%$ do número e $28,8 \%$ do peso total capturado em arrastos de fundo experimentais (ARAÚJO et al., 1988). Cinco espécies de Ariidae foram registradas nesta Baía: Genidens genidens (Valenciennes, 1839), Netuna barba (Lacépede, 1803), Cathorops spixii (Agassiz, 1829), Sciadeichthys luniscutis (Valenciennes, 1840) e Bagre marinus (Mitchill, 1814). Em Peruíbe e Ubatuba foi identificada a ocorrência das espécies Cathorops spixii e Genidens barbus. Na Baía de Paranaguá e de Guaratuba (PR), as espécies Cathorops spixii e Genidens barbus também foram relatadas (QUEIROZ, 2006). Na 
Amazônia brasileira, Colômbia, Peru, Bolívia e Venezuela algumas espécies de bagres representam $95 \%$ da captura de pescado (BATISTA et al., 2005), e na Amazônia, a maior parte da produção de bagres $(85 \%)$ é exportada para Letícia, na Colômbia, e este fato se deve a uma rejeição deste produto à nível local por questões culturais (PARENTE et al.,2005).

No ano de 2011, a produção nacional de pescado apresentou um aumento de $13,2 \%$ em relação ao ano de 2010, produção esta de 1.431.974,4 t. Quanto à produção nacional segundo o tipo de pesca, a pesca extrativa marinha é a principal fonte de produção de pescado nacional (Tabela 3), apresentando aumento de $2,3 \%$ em relação à produção total de pesca extrativa no ano de 2010. Quanto à produção por estado, a Bahia, Rio Grande do Sul, São Paulo, Mato Grosso, Alagoas, Sergipe e Distrito Federal apresentaram uma redução em relação ao produzido em 2010, mas para os demais estados foi observado um incremento na produção de pescado em relação ao ano de 2010 (BRASIL, 2011).

Tabela 3. Produção nacional de pescado segundo o tipo de pesca, expressa em percentual (\%) e em toneladas (t), no ano de 2011

\begin{tabular}{lcc}
\hline Tipo de pesca & Percentual (\%) & $\begin{array}{c}\text { Produção em } \\
\text { toneladas (t) }\end{array}$ \\
\hline Pesca Extrativa Marinha & 38,7 & $553.670,0$ \\
Aquicultura Continental & 38 & $544.490,0$ \\
Pesca Extrativa Continental & 17,4 & $249.600,2$ \\
Aquicultura Marinha & 6 & $84.214,3$ \\
\hline
\end{tabular}

Fonte: Brasil, 2011.

Ao avaliar a produção marinha nacional por espécie, a maior produção foi observada no grupo dos peixes (Tabela 4). Dessa forma, a produção pesqueira marinha teve um incremento de 3,6\% em relação a 2010. Dentre as espécies mais capturadas, a sardinha-verdadeira liderou o maior volume desembarcado (Tabela 5), apresentando um acréscimo de $21 \%$ em relação a 2010, seguida da corvina, e o grupo de outros peixes, dentre os quais o bagre está incluído, representou a terceira espécie mais capturada. $\mathrm{O}$ bonitolistrado representou um aumento de $48 \%$ em relação a 2010 , sendo a quarta espécie mais capturada (BRASIL, 2011).

Tabela 4. Produção marinha nacional por espécie, expressa em percentual (\%), no ano de 2011

\begin{tabular}{lc}
\hline Espécie & Produção em percentual (\%) \\
\hline Grupo dos peixes & 87 \\
Crustáceos & 10 \\
Moluscos & 3 \\
\hline
\end{tabular}

Fonte: Brasil, 2011.

Tabela 5. Espécies mais capturadas no Brasil, expressas em percentual (\%), e em toneladas (t), no ano de 2011

\begin{tabular}{lc}
\hline Espécies mais capturadas & Montante em Toneladas (t) \\
\hline Sardinha- verdadeira & $75.122,5$ \\
Corvina & $43.369,7$ \\
Bagre e outros peixes & $40.168,2$ \\
Bonito-listrado & $30.563,3$ \\
\hline
\end{tabular}

Fonte: Brasil, 2011.
Verifica-se na atualidade no mercado brasileiro de pescado é um déficit na balança comercial, o que significa que há maior peso nas importações que exportações. As importações são evidenciadas na demanda de espécies que não são encontradas na costa, como o salmão e bacalhau, mas também para suprir a demanda da produção do mercado interno, como a pescada e sardinha. Em 2011, esse déficit nas exportações foi de aproximadamente US\$ 991 milhões, representando uma elevação de $32,5 \%$ em relação ao déficit de 2010, de aproximadamente US\$ 748 milhões. Peixes, crustáceos e moluscos apresentam a maior relevância na balança comercial, representando $74 \%$ das exportações e importações para peixes e $94 \%$ para crustáceos e moluscos (BRASIL, 2011).

A produção pesqueira do estado do Rio de Janeiro abriga o $2^{\circ}$ maior mercado consumidor do país e ocupa a $4^{\mathrm{a}}$ posição na produção nacional de pescado, com uma produção de aproximadamente 57.000 toneladas (MPA, 2012), sendo a sardinha-verdadeira (Sardinella brasiliensis) e a sardinha boca-torta (Cetengraulis edentulus) as espécies de maior importância na produção do Estado do Rio de Janeiro, e seus estoques encontram-se em situação de sobrepesca (BRASIL, 2011).

\section{QUALIDADE E VALOR NUTRICIONAL DE ESPÉCIES DE BAGRE}

Os benefícios nutricionais proporcionados pela ingestão de pescado são associados a fontes proteicas de elevado valor biológico, alto teor de ácido graxo poliinsaturado ômega 3, baixo teor de colesterol, e fonte de vitamina A e D (OGAWA, MAIA, 1999), além de conferir fácil digestibilidade devido ao baixo teor de tecido conjuntivo, e portanto, requerem uma inserção sólida no mercado de alimentos, tendo em vista a preocupação da população por hábitos alimentares mais saudáveis (WIDJAJA et al., 2009).

No entanto, o elevado preço de aquisição deste produto e a elevada competitividade comparada com as demais fontes proteicas de origem animal oferecidas no mercado, conferem um fator limitante para atingir um elevado consumo per capita, e considerando que o setor pesqueiro no Brasil representa aproximadamente $0,4 \%$ do PIB, este percentual possui capacidade de se ampliar consideravelmente (WIDJAJA et al., 2009; BRASIL, 2011). Isto é criticado por ambientalistas devido ao fato de muitas espécies produzidas se encontrarem numa situação de sobrepesca, sendo a prática de pesca sustentável dentro de uma gestão costeira uma solução para estas questões (SILVEIRA, 2009).

A composição química do músculo do pescado pode ser variável de acordo com a espécie, apresentando em média 70 a $85 \%$ de água, 20 a $25 \%$ de proteínas, 0,2 a $25 \%$ de gordura, 0,1 a $1 \%$ de glicídios, e 1 a $1,5 \%$ de minerais (OGAWA; MAIA,1999) e em cada 100 gramas 93,7 quilocalorias, 1,7g de gorduras, 19,6g de proteínas, $27 \mathrm{mg}$ de cálcio,197 mg de fósforo, 0,8 mg de ferro, 0,04 mg de vitamina B1 e 0,08 mg de vitamina B2 (OETTERER, 2004).

A água no músculo é o componente mais abundante, e varia inversamente com o teor de gordura, uma vez que o teor de umidade por volta de $60 \%$ representa um peixe com elevado teor de gordura, e teores de umidade por volta de $80 \%$ representam um peixe com baixo teor de gordura (GONÇALVES, 2011). As proteínas presentes no pescado possuem elevado valor biológico e alta digestibilidade, o que 
significa a presença de todos os aminoácidos essenciais. A proteína presente no tecido muscular é classificada em três grupos: proteínas estruturais, como actina, miosina, tropomiosina, estas que constituem 70 a $80 \%$ do teor de proteína total; proteínas sarcoplasmáticas, como globulina, mioglobina, constituindo 25 a $30 \%$ do teor de proteína total; proteínas do tecido conjuntivo, como colágeno e elastina, constituindo em média 3\% em peixes teleósteos e $10 \%$ em peixes elasmobrânquios (GONÇALVES, 2011).

Os lipídios presentes no pescado apresentam sua relevância pelo fato de apresentarem baixo percentual de ácidos graxos saturados e um elevado percentual de ácidos graxos polinsaturados, os quais são presentes ômega-3, como os ácidos eicosapentanóico (EPA, 20:5 @ 3 ) e docosahexanóico (DHA, 22:6 Ф3), estes amplamente estudados quanto suas ações benéficas na prevenção de doenças cardiovasculares, diabetes e no sistema imunológico (SARTORI; AMANCIO, 2012).

Os produtos de pesca, sobretudo marinhos são importantes fontes de minerais, podendo variar de 0,8 a $2 \%$, e em ordem decrescente de concentrações e na maioria das espécies estão presentes os respectivos compostos: potássio, fósforo, sódio, magnésio, cálcio, zinco e ferro (NUNES et al., 2008).

De acordo com Figueiredo (2009) entre outras espécies estudadas, o Genidens barbus apresentou 1,22g de lipídios na carne em $100 \mathrm{~g}$ de amostra e 4,32g de lipídios na pele, em $100 \mathrm{~g}$ de amostra, apresentando este último teor bem inferior quando comparados à pele de frango $(56 \mathrm{~g} / 100 \mathrm{~g})$, apresentado por (BRAGAGNOLO, 2001).

Quanto ao teor de colesterol na carne, esta espécie apresentou 41,62 mg/100g de amostra, e 33,53 mg/100g de amostra para o teor de colesterol na pele. Esta espécie se comparada à outras de importância econômica, como a sardinha-verdadeira (Sardinella brasiliensis) e a sardinha boca-torta (Cetengraulis edentulus), correspondem àquelas com menores teores de lipídeos e colesterol, e o perfil de ácidos graxos é similar a dos peixes de outras regiões do Brasil, portanto representam alimento de grande relevância nutricional (FIGUEIREDO, 2009).

O teor lipídico pode ser influenciado por vários fatores como sexo, idade reprodutiva, estado fisiológico, salinidade, temperatura, alimentação, sendo variável de acordo com a época do ano e localização geográfica. Quanto ao teor de gordura na musculatura, as espécies podem ser classificadas como magras, semi- gordas e gordas (GONÇALVES, 2011), sendo que a musculatura clara apresenta menor quantidade de lipídios que a musculatura escura (HUSS, 1997).

Quanto ao perfil de ácidos graxos, o mais representativo foi o ácido palmítico (Tabela 6).

Tabela 6. Perfil de ácidos graxos de Genidens barbus, expressos em percentual (\%)

\begin{tabular}{ll}
\hline \multicolumn{2}{c}{ Perfil de Ácidos Graxos (\%) } \\
\hline Ácido Mirístico & 6,19 \\
Ácido Palmítico & 36,43 \\
Ácido Esteárico & 13,22 \\
Ácido Palmitolêico & 9,96 \\
Ácido Olêico & 13,18 \\
Ácido Vacênico & 5,84 \\
Ácido Docosahexanóico & 4,52 \\
Ácido Docosapentanóico & 5,15 \\
\hline Fonte: Figueiredo, 2009.
\end{tabular}

Ressalta-se, dentre os ácidos graxos que foram predominantes, o ácido mirístico possui maior potencialidade hipercolesterolêmica e aterogênica (KRIS-ETHERTON, 1997), porém o ácido palmítico também possui grande relevância quanto ao risco de desenvolvimento de doenças cardiovasculares, sendo encontrado no bagre-branco em valores muito mais significativos (CURI et. al., 2002). Quanto aos ácidos graxos monoinsaturados, o oléico, foi observado em predominância e relevância devido à capacidade de reduzir os níveis séricos de colesterol e triacilgliceróis quando substitui a gordura saturada na dieta (MAHAN;ESCOTT-STUMP, 2005).

Tabela 7. Composição Centesimal de Cathorops spixii em $100 \mathrm{~g}$ de produto in natura e processado, através de salga e secagem

\begin{tabular}{lcr}
\hline $\begin{array}{l}\text { Composição } \\
\text { Centesimal }\end{array}$ & $\begin{array}{c}\text { Produto in natura } \\
(\mathrm{g} / 100 \mathrm{~g})\end{array}$ & $\begin{array}{l}\text { Produto processado } \\
(\mathrm{g} / 100 \mathrm{~g})\end{array}$ \\
\hline Umidade & 70,13 & 40,31 \\
Cinzas & 4,84 & 23,18 \\
Proteínas & 51,73 & 38,07 \\
Lipídios & 8,67 & 13,58 \\
Carboidratos & 1,39 & 1,40 \\
Valor Calórico & $486 \mathrm{Kcal}$ & $367 \mathrm{Kcal}$ \\
Cloretos & 0,85 & 17,02 \\
\hline
\end{tabular}

Fonte: Oliveira et al., 2008

Dentre os 22 ácidos graxos detectados no bagre-amarelo (Cathorops spixii) (Tabela 8), o ácido palmítico ocorreu em maior abundância, e em segundo, o ácido olêico (OLIVEIRA et. al, 2008), o qual possui relevância na capacidade de redução dos níveis séricos de colesterol e triacilgliceróis (MAHAN, 2002).

Tabela 8. Perfil de ácidos graxos de maior predominância no bagre-amarelo, expressos em percentual (\%), no produto in natura, e processado através dos métodos de salga e secagem

\begin{tabular}{lcc}
\hline Ácidos Graxos & $\begin{array}{c}\text { Produto in } \\
\text { natura }(\%)\end{array}$ & $\begin{array}{c}\text { Produto salgado } \\
\text { e seco }(\%)\end{array}$ \\
\hline Ácido palmítico (C16:0) & 41,19 & 39,80 \\
Ácido oleico (C18:1n9) & 16,72 & 17,60 \\
Ácido esteárico (C18:0) & 10,40 & 9,43 \\
Ácido palmitolêico (C16:1n7) & 7,09 & 7,70 \\
\hline
\end{tabular}

Fonte: Oliveira et al., 2008

Quanto aos ácidos graxos poliinsaturados formas importantes de ômega-3 e ômega-6 foram detectados no bagre-amarelo in natura e salgado-seco (Tabela 9) (OLIVEIRA et al., 2008). Esses ácidos graxos poliinsaturados são considerados essenciais, pois só podem ser adquiridos na dieta, e contribuem positivamente no sistema cardiovascular, imunológico, neurológico, além dos impactos também positivos em doenças de pele, insuficiência reprodutiva, câncer e algumas doenças crônicas (WIDJAJA et al., 2009). A diminuição da concentração de colesterol no bagre-amarelo processado foi associada à degradação desse esterol que é instável sob condições de luz, calor, presença de radicais livres, oxigênio, metais de transição, favorecendo a sua oxidação (PANIANGVAIT et al., 1995; SAMPAIO, 2004). 
Tabela 9. Perfil de ácidos graxos poliinsaturados no bagreamarelo na forma in natura, e processada através de método de salga e secagem, expressos em percentual

\begin{tabular}{lcc}
\hline Ácidos Graxos Poliinsaturados & $\begin{array}{c}\text { Produto in } \\
\text { natura (\%) }\end{array}$ & $\begin{array}{c}\text { Produto } \\
\text { salgado e } \\
\text { seco (\%) }\end{array}$ \\
\hline Ácido Docosahexanóico(C22:6n3) & 3,87 & 2,19 \\
$\alpha$ linolêico (C18:3n3) & 2,09 & 1,77 \\
Ácido eicosapentanóico(C20:5n3) & 1,57 & 1,88 \\
Ácido linolêico (C18:2n6) & 2,55 & 1,62 \\
\hline Fonte: Oliveira et al., 2008
\end{tabular}

Fonte: Oliveira et al., 2008.

\section{AGREgAÇÃO DE VALOR AO PESCADO ATRAVÉS DO USO SUSTENTÁVEL DE TECNOLOGIAS TRADICIONAIS- SALGA E SECAGEM}

A salga consiste num método de conservação adquirido através da redução da água livre do pescado por processo de osmose numa concentração de sal superior a $10 \%$ (AIURA et al., 2008). A capacidade conservadora do sal se deve à ação do cloreto de sódio sobre as células bacterianas, a fim de elevar a pressão osmótica, causando o rompimento dessas (BASTOS, 1988; SANTANA et al., 2009), além disso, o $\mathrm{NaCl}$ bloqueia o núcleo das proteínas bacterianas, possuindo efeito bactericida e bacteriostático (BASTOS, 1988). Um fator favorável à penetração do sal é a permeabilidade das membranas dos tecidos dos peixes que ocorre no processo pós mortem (OGAWA; MAIA, 1999), e a redução da atividade de água inibem as enzimas do pescado e os microorganismos responsáveis pelo processo de deterioração (OGAWA, MAIA, 1999). Além disso, agrega valor financeiro ao produto, pois fornece ao consumidor um alimento com características organolépticas diferenciadas dos demais devido ao seu aroma, sabor e forma de apresentação (GONÇALVES, 2011).

A salga é difundida em várias regiões do litoral brasileiro, principalmente em regiões precárias de transporte ou energia elétrica (BRESSAN; PEREZ, 2001), e com a dificuldade de comercialização do pescado fresco, este pode ser destinado a salga em precárias condições de processamento tecnológico, comprometendo de fato a qualidade do produto final (OLIVEIRA, 2007), e devido a isso há necessidade de se aprimorar as técnicas de processamento a fim de gerar um produto com qualidade sanitária e sensorial adequada ao consumidor. A escolha do método de salga é feita de acordo com o tipo de pescado, tamanho e grau de frescor e principalmente de acordo com o teor de gordura existente na espécie em questão, uma vez que a difusão do sal ocorre inversamente proporcional ao teor de gordura (GONÇALVES, 2011), porém, são avaliados também fatores de ordem econômica e cultural (OGAWA; MAIA, 1999). Mas, o princípio da salga independe do método utilizado, e será obtida quando se dá o equilíbrio osmótico próximo a $80 \%$ e com conteúdo de sal próximo a $17 \%$ (OGAWA; MAIA, 1999; GONÇALVES, 2011).

Quanto ao pescado salgado no Brasil, a espécie Cathorops spixii é consumida popularmente na região do entorno do Complexo Estuarino das Lagoas Mundaú/Manguaba, estado de Alagoas, não sendo um peixe de valor comercial, mas de grande valor social, devido ao seu baixo custo. Em Pernambuco, os bagres também são comercializados sob a forma salgada e levados a pontos mais distantes da costa (VERÍSSIMO, 1970; GUEDES; VASCONCELOS, 1980). No Município de Itaguaí, RJ, em determinadas épocas do ano, há demanda de comercialização do bagre, que é feita sob a forma salgada e seca, denominado popularmente de "mulato velho".

A secagem atua como uma complementação preservativa do processo de salga, e seu princípio consiste na passagem da água do centro do produto até a superfície, com consequente evaporação (SALVADOR, 2011), apresentando ao final umidade inferior a 25\% (OGAWA; MAIA, 1999).A secagem, por sua vez, é influenciada por diversos fatores, como: umidade do produto, tamanho e forma do filé, teor de gordura, superfície do filé, espaçamento entre as postas e condições termodinâmicas (BASTOS, 1988). A secagem natural ocorre com a presença do calor solar e movimento do ar, porém, esta só será efetiva em presença de baixa umidade relativa do ar (CASTRO, 2009).

Assim como a salga, a secagem é um método muito antigo, mas que atualmente vem sendo cada vez mais aprimorado, sendo um processo economicamente favorável devido à sua simplicidade e menores gastos de energia. Os impactos ambientais causados pela utilização dos combustíveis fósseis tem sido assunto de discussão em todo o mundo devido aos danos causados à saúde das pessoas, destroem a natureza e contribuem para o aquecimento global do planeta. Em virtude disso muitos países estão procurando fontes alternativas para a substituição dos combustíveis fósseis, procurando uma fonte de energia que afete menos o meio ambiente, a vida das pessoas, que possam ser encontradas facilmente e em abundância na natureza. A melhor alternativa encontrada são as fontes de biomassa, eólica, hídrica e solar, fontes renováveis de energia, aquelas que os nossos antepassados já utilizavam (DA SILVA et al., 2013).

A secagem através de energia renovável é um método economicamente viável e se torna boa alternativa ao consumo, visando o aproveitamento de espécies subutilizadas e que possuem excelentes propriedades nutricionais, além das características sensoriais desejáveis obtidas pelo processo de salga/secagem, que são de boa aceitabilidade pelo consumidor, como ocorre no Município de Itaguaí, RJ. A identificação e caracterização de novas fontes de aproveitamento do pescado possibilitará uma maior incorporação de produtos à base de pescado na cadeia produtiva, possibilitando desta forma, a obtenção de produtos com valor agregado, maior oferta e diversificação dos produtos elaborados, com qualidade nutricional e microbiológica para o consumo.

O Brasil possui considerável tradição no uso de fontes renováveis de energia, especialmente a energia hidráulica, o carvão vegetal e o etanol. Contudo, as fontes de energia reconhecidas em todo o mundo como renováveis - solar, eólica, e biomassa, têm tido recente destaque como forma de suprir ou complementar o mercado (PEREIRA, 2000).

O sol constitui uma fonte de energia inesgotável, gratuita e pode ser usada de diversas formas como energia renovável. A secagem dos alimentos através da utilização da energia solar é um método ancestral de conservação dos alimentos simples e de baixo custo. No entanto, a secagem direta ao sol permite que o alimento esteja mais exposto à poeira, insetos e as perdas são maiores, além de não permitir a obtenção de produtos de boa qualidade, sendo necessário o emprego de boas práticas de fabricação (BPF) para redução 
da contaminação e das perdas ao longo do processamento. Já na secagem artificial, os secadores convencionais exigem elevado investimento, custos operacionais e de energia, além de mão-de-obra especializada, e os secadores solares contribuem para minimizar essas desvantagens (DA SILVA et al., 2013).

O uso de secadores solares possibilita que o processamento dos produtos possa ser feito com baixo investimento inicial, exige treinamento básico para sua operação, e visa incentivar a valorização da pesca artesanal através da utilização de técnicas simples e eficientes, e, com o intuito do aproveitamento de espécies de pouco valor comercial no mercado consumidor, permite agregar valor ao produto final, visando também estimular a sua inserção no mercado (DA SILVA et al., 2013). O fato dos secadores solares utilizarem energia limpa e renovável torna o produto mais competitivo, proporcionando melhoria na renda e na qualidade de vida de comunidades pesqueiras, estando também em acordo com os objetivos de um desenvolvimento sustentável (REZENDE et al., 2007). A transferência desta tecnologia possibilita a obtenção desta pelo pescador para a ampliação de sua escala de produção em períodos de menor safra de pesca. Sendo assim, é esperado também que haja articulação entre os órgãos governamentais para 0 desenvolvimento de políticas públicas eficientes voltadas para os pescadores artesanais, além da criação de linhas de crédito para que estes consigam implementar de maneira viável as unidades de secagem em suas propriedades (REZENDE, 2007).

A utilização destas fontes de energias renováveis tende a reduzir o desperdício de alimentos, principalmente no que está relacionado ao uso de espécies de pescado subutilizadas ou sem valor no mercado consumidor e promover renda adicional para as comunidades pesqueiras envolvidas. As grandes indústrias são as principais fontes geradoras de empregos, mas atualmente torna-se necessário um feedback entre crescimento econômico, exploração de recursos naturais, qualidade de vida e distribuição de renda, ou seja, um desenvolvimento sustentável (REZENDE et al., 2007).

\section{CONSIDERAÇÕES FINAIS}

Aliar os conhecimentos técnico-científicos a partir da inserção de tecnologias sociais para o desenvolvimento de produtos alimentícios a base de pescado subutilizado permitirá melhorias na qualidade de vida de pescadores artesanais agregando valor ao pescado e à atividade pesqueira, sob a ótica da produção sustentável, para o fortalecimento dessas comunidades. Desta forma, isso se traduz na geração do aumento da renda familiar com o aproveitamento dos excedentes, além da capitalização do pescador possibilitando o desenvolvimento da economia local, além do estímulo à comercialização de um produto feito de forma artesanal, com maior valor agregado, e, por utilizar energia limpa e renovável torna o produto mais competitivo no mercado, podendo também ser oferecido aos turistas que chegam à região. Além disso, o uso de secadores solares possibilita que o processamento dos produtos possa ser feito com baixo investimento inicial, exigindo apenas treinamento básico para sua operação. Permite-se também estimular o fortalecimento de pequenas indústrias do Estado do Rio de Janeiro que fabricam e comercializam motores eólicos, coletores solares e seus acessórios para a secagem de produtos agropecuários. Portanto, é esperado também que haja articulação entre os órgãos governamentais para o desenvolvimento de políticas públicas eficientes voltadas para o segmento artesanal da cadeia produtiva da pesca, além da criação de linhas de crédito para que estes consigam implementar de maneira viável as unidades de secagem em suas propriedades.

\section{REFERÊNCIAS BIBLIOGRÁFICAS}

AIURA, F. S. et al. Conservação de filés de tilápia-do-nilo (Oreochromis niloticus) em salga seca e úmida. Arq. Bras. Med. Vet. Zootec. Belo Horizonte, v. 60, n. 6, p. 15311537. 2008.

AMARAL, A. C. Z. ; MIGOTTO, A. E. Importância dos anelídeos poliquetas na alimentação da macrofauna demersal e epibentônica da região de Ubatuba. Instituto Oceanográfico USP, São Paulo, 1980, v. 29, n. 2, p 31 35.1980 .

ARAÚJO, F.G. Distribuição, abundância, movimentos sazonais e hábitos alimentares de bagres marinhos (Siluriformes, Ariidae) no estuário da Lagoa dos Patos (RS), Brasil. 1983. Dissertação de Mestrado em Oceanografia Biológica, Fundação Universidade Federal do Rio Grande 89p.

ARAÚJO, F.G. Distribuição, abundância relativa e movimentos sazonais de bagres marinhos(Siluriformes, Ariidae) no estuário da Lagoa dos Patos (RS), Brasil. Revta bras. Zoo.I. 5 (4): 509-543. 1988.

ARAÚJO, F.G.; CRUZ-FILHO, A.G. de; AZEVEDO, M.C.C.; SANTOS, A.C. de A. Estrutura da comunidade de peixes demersais da Baía de Sepetiba, RJ. Rev. Brasil. Biol., 58 (3): 417-430.1998.

AZEVEDO, M.C.C; ARAÚJO, F.G.; FILHO, A.G.G.; SANTOS, A.C.A. Distribuição e abundância relativa de bagres marinhos (Siluriformes, Ariidae) na Baía de Sepetiba, Rio de Janeiro. Revista brasilerira de Zoologia. 15 (4): 853 - 865, 1998.

BATISTA, J.; DÁVILA, C. R. G.; MARÃO-SIQUEIRA, T.; RUIZ, D. C.; MACUYAMA, W. C.; FORMIGAAQUINO, K.; ALVES-GOMES, J. A. Genética Populacional da Dourada - Brachyplatystoma rousseauxii (Pimelodidae - Siluriformes) na Amazônia Brasileira e Peruana. Coloquio Internacional de la Red de Investigación sobre la Ictiofauna Amazónica, I, 2005. Anais. Iquitos: [S.N.], 2005.

BASTOS, J. R.; Processamento e Conservação do Pescado. In: Manual sobre Manejo de Reservatórios para Produção de Peixes. Programa Cooperativo Governamental, FAO: Itália, 1988. Disponível em: < http://www.fao.org/docrep/field/003/AB486P/AB486P07. htm >. Acesso em: 17 de agosto de 2013.

BRAGAGNOLO, N. Aspectos Comparativos entre Carnes Segundo a Composição de Ácidos graxos e Teor de Colesterol. In: II Conferência Internacional Virtual sobre Qualidade de Carne Suína. 2001. 
BRASIL. Ministério da Pesca e Aquicultura - MPA. Boletim Estatístico da Pesca e Aquicultura 2010, p. 25. <http://www.mpa.gov.br/images/Docs/Informacoes_e_Est atisticas/Boletim\%20Esta\%C3\%

Dstico\%20MPA\%202010.pdf> Acesso em: 11 jul.2013.

BRASIL. Ministério da Pesca e Aquicultura - MPA. Boletim Estatístico da Pesca e Aquicultura 2011, p.21, 25, 39.

BRASIL. Ministério da Pesca e Aquicultura - MPA. Disponível em http://www.mpa.gov.br/pesca. Acessado em 21/04/15.

BRESSAN, M. C.; PEREZ, J. R. O. Tecnologia de Carnes e Pescados. Lavras - MG: Universidade Federal de Lavras, 2001, 240 p.

CASTRO, G. L. M.; Avaliação da qualidade sanitária do pescado salgado seco comercializado nas feiras livres de Belém-PA. 2009. 46 p. Tese (TCC de higiene e inspeção de produtos de origem animal- HIPOA). Universidade Castelo Branco, Centro de Ciências Agrárias, Belém.

CURI, R.; Pompéia, C.; MIYASAKA, K. ; PROCÓPIO, J. Entendendo as gorduras - os ácidos graxos. 1.ed. São Paulo: Editora Manole, 2002, 580p.

DA SILVA, D.G.; LOPES, R.P.; CARVALHO, D.F. Caracterização do potencial eólico em Seropédica (RJ). Energ. Agric., Botucatu, vol. 28, n.3, p.185-192, julhosetembro, 2013.

FAO. Fao yearbook: The state of world fisheries and aquaculture: Oportunities and challenges. Disponível em: http://www.fao.org/3/a-i3720e.pdf. Roma: FAO, 2014.

FIGUEIREDO, J.L.; MENEZES, N.A. Manual de peixes marinhos do Sudeste do Brasil: II Teleostei (1) São Paulo: Museu de Zoologia, 1978.110 p.

FIGUEIREDO, P.N.V. Perfil lipídico de cinco espécies de peixes capturados na região do Oiapoque-Amapá. 2009. Dissertação apresentada ao Programa de Pós-Graduação em Ciências Veterinárias da Faculdade de Veterinária da Universidade Estadual do Ceará, como requisito parcial para a obtenção do grau de Mestre em Ciências Veterinárias, Fortaleza.

GOMES, I.D.; F.G. ARAÚJO; M.C.C.; AZEVEDO \& A.L.M. PESSANHA. Biologia reprodutiva dos bagres marinhos Genidens genidens (Valencianes) e Cathorops spixii (Agassiz) (Siruliformes, Ariidae) na Baía de Sepetiba, Rio de Janeiro, Brasil. Revista Brasileira de Zoologia, Curitiba, 16 (2): 171-180. 1999.

GONÇALVES, S. M. N. S.; Bacalhau Salgado Seco: Influência da demolha e do tratamento culinário na sua qualidade. 2011. 145 p. Tese (Mestrado em Tecnologia e Segurança Alimentar). Faculdade de Ciências e Tecnologia, Universidade Nova de Lisboa.

GUEDES ,D.S.; Vasconcelos, F.A.L. Estudo Ecológico da Região de Itamaracá, Pernambuco, Brasil, XI. Informações sobre a Alimentação dos bagres Branco e Amarelo (Pisces, Ariidae): trabalhos oceano gráficos da Universidade Federal de Pernambuco.In: Congresso
Brasileiro de Zoologia,11.,1980, v.15, p.323-330. São Paulo: SBI, 1980. p.248.

HAHN, N.S.; FUGI, R.; ALMEIDA, V.L.L. de; RUSSO, M.R.; LOUREIRO, V.E. Dieta e atividade alimentar de peixes do reservatório de Segredo. In: Agostinho, A.A. \& Gomes, L.C. Reservatório de Segredo: bases ecológicas para o manejo. Maringá; Eduem. P. 141-162.1997.

HOSTIM-SILVA, M.; VERANI, J. R.; BRANCO, J. O.; LEITE, J. R. Reprodução do bagre Genidens genidens (Siluriformes, Ariidae) na Foz do Rio Itajaí-Açú, SC., 227-248p. In: Joaquim Olinto Branco; Maria José Lunardon-Branco \& Valéria Regina Bellotto (Org.). Estuário do Rio Itajaí-Açú, Santa Catarina: caracterização ambiental e alterações antrópicas. Editora UNIVALI, Itajaí, SC., 2009, 312p.

KRIS-ETHERTON, P. M; YU, S. Individual fatty acid effects on plasma lipids and lipoproteins: human studies. Am. J. Clin. Nutr., v.65, Suppl.1, p.1628-1644, 1997.

MARCENIUK, A.P. Chave para identificação das espécies de bagres marinhos (Siluriformes, Ariidae) da Costa Brasileira. Boletim Instituto de Pesca, São Paulo, 31(2): 89 - 101, 2005.

MARCENIUK, A. P. Redescrição de Genidens barbus (Lacépède, 1803) e Genidens machadoi (Miranda-Ribeiro, 1918), bagres marinhos (Siluriformes, Ariidae) do Atlântico Sul Ocidental. Papéis Avulsos de Zoologia (São Paulo), v.45, p. 111-125. 2005.

MAHAN, L.K.; ESCOTT-STUMP, S.K. Alimentos, Nutrição e dietoterapia. 9 ed. São. Paulo: Rocca, 2005, p.43.

MARTINS, D.G.; Martins, I.M.; Hanazaki, N. Desembarque de peixes da pesca artesanal na Barra do Rio, Tijucas, SC, Brasil. Biotemas, 26 (2): 237-247, junho de 2013.

MISHIMA, M. \& Tanji S. 1983. Fatores ambientais relacionados a distribuição e abundância de bagres marinhos (Osteichthyes, Ariidae) no complexo estuarino lagunar de Cananéia $\left(25^{\circ} \mathrm{S}, 48^{\circ} \mathrm{W}\right)$. Boletim do Instituto de Pesca de São Paulo,10:17-27.

MENDES, F.L.S.; Barthem, R.B. Hábitos alimentares de bagres marinhos (Siluriformes: Ariidae) do estuário amazônico. Amazônia: Ci \& Desenv., Belém, v.5, n.10, jan./jun.2010.

MENDONÇA, J.T. Gestão dos recursos pesqueiros do Complexo-Estuarino-Lagunar de Cananéia-Iguapé- Ilha Comprida, Litoral Sul de São Paulo, Brasil. 2008. Tese apresentada à Universidade Federal de São Carlos para obtenção do título de doutor em Ciências.

MENEZES, N.A.; Buckup, P.A., FIGUEIREDO, J.L. \& MOURA, R.L. Catálogo das espécies de peixes marinhos do Brasil. Museu de Zoologia da Universidade de São Paulo, São Paulo. 2003.

NUNES, M. L. et. al.: Produtos da pesca: Valor nutricional e importância para a saúde e bem-estar dos consumidores. 2008. 
OETTERER, M. Industrialização do pescado cultivado. Livraria e Editora Agropecuária. 2002.

OGAWA, M.; Maia, E.L. Manual de pesca. São Paulo: Varella, 430p. 1999.

OLIVEIRA, A.F.; BEMVENUTTI, M.A. O ciclo de vida de alguns peixes do Estuário da Lagoa dos Patos, RS, informações para o ensino fundamental e médio. Cadernos de Ecologia Aquática 1 (2) :16-29, ago -dez 2006.

OLIVEIRA, P.R. de. Qualidade do pirarucu (Arapaima gigas, Schinz 1822) procedente de piscicultura, estocado em gelo, congelado e de seus produtos derivados. Manaus, 2007. 119 f. Tese (Doutorado em Biologia Tropical e Recursos Naturais da Amazônia) - Instituto Nacional de Pesquisas da Amazônia, Universidade Federal do Amazonas, Manaus.

OLIVEIRA,F.R.; LIRA, G.M.;TORRES, E.A.F.S.; SOARES, R.A.M.; MENDONÇA, S.; DA SILVA, K.W.B.; SIMON, S.J.G.B.; SANTOS, T.M.P.; JUNIOR, S.R.C. Efeito do beneficiamento sobre o valor nutricional do peixe mandim (Arius spixii). Revista Brasileira de Ciências Farmacêuticas Brazilian Journal of Pharmaceutical Sciences vol. 44, n. 4, out./dez., 2008.

PANIANGVA, P.; KING, A.J.; JONES, A. D.; GERMAN,B.G. A critical review cholesterol oxides in foods of animal origin. J. Food Sci., v.60, n.6, p.11591174, 1995.

PARENTE, V.M.; VIEIRA, E.F.; CARVALHO, A.R.; FABRÉ, N.N. A Pesca e a economia da pesca de bagres no eixo Solimões-Amazonas. In: FABRÉ, N.N.; BARTHEM, R.B. (orgs.) O manejo da pesca dos grandes bagres migradores: piramutaba e dourada no eixo Solimões-Amazonas. Manaus: IBAMA; PROVÁRZEA. Coleção Documentos Técnicos: estudos estratégicos. 2005.

PEREIRA, O.L.S. Situação e Perspectivas das Novas Fontes de Energia Renovável no Brasil. Relatório elaborado para o Ministério de Ciência e Tecnologia, dentro do projeto BRA95G31, sob o de contrato de $n^{\circ}$ 99/117, com o Programa das Nações Unidas para o Desenvolvimento PNUD, 2000.

QUEIROZ, G. M. N de; SPACH, H. L.; MORELOS, M. S.; SANTOS, L. O.; JUNIOR, R. S. Caracterização da ictiofauna demersal de duas áreas do complexo estuarino de Paranaguá, Paraná, Brasil. Biocências. v. 14(2), p. 112124, 2006.

REIS, E.G. A pesca artesanal de bagres marinhos (Silurifornes, Ariidae) no estuário da Lagoa dos Patos (RS), Brasil. Rio Grande, FURG, Documentos técnicos 5, 22p.1986.

REZENDE, A.A.; MIYAJI, M.; CHAVES, M.A.; SILVA, A.A.L. Secagem de Alimentos por Fontes de Energia Renováveis: Possibilidade de Geração de Renda para o Pequeno Produtor Rural do Sudoeste Baiano. XLV
Congresso Sociedade Brasileira de Economia, Administração e Sociologia Rural- Sober, Londrina, 2007.

SALVADOR, A. M. C. Efeito de alta pressão no processo de demolha de bacalhau. 2009. 86 p. Tese (Mestrado em Bioquímica e Química dos Alimentos). Departamento de Química, Universidade de Aveiro.

SAMPAIO, G. R. Ocorrência de óxidos de colesterol e análise do perfil lipídico em camarão salgado-seco. São Paulo, 2004. 93p. Dissertação de Mestrado. Faculdade de Saúde Pública. Departamento de Nutrição- Universidade de São Paulo.

SANTANA, F. M. S.; SANTOS, P. A. F.; LINS, L. H. C.; ARAÚJO NETO, E. T.; SILVA, S. L.; SILVA, B. C. L.; LIMA, H. C. Rendimento da Tainha Mugil corema (Valenciennes, 1836) Submetida ao Processo de Salga Mista. In: Jornada de Ensino Pesquisa e Extensão, 9., 2009, Recife. Anais eletrônicos Recife: UFRPE, Universidade Federal Rural de Pernambuco, 2009. Disponível em:<http://www.eventosufrpe.com.br/jepex2009/cd/listare sumos.htm>. Acesso em: 02 julho. 2013.

SANTANA, F.M.S.; SILVA, A. C. G.; SEVERI, W. Anais do VIII Congresso de Ecologia do Brasil, 23 a 28 de Setembro de 2007, Caxambu - MG. 2007.

SARTORI, A.G.O.; AMANCIO, R.D. Importância nutricional e consumo no Brasil. Segurança Alimentar e Nutricional, Campinas, 19 (2): 83-93, 2012.

SCHMIDT, T.C.S., MARTINS, I.A., REIGADA, A.L.D. \& DIAS, J.F. Taxocenose of marine catfish (Siluriformes, Ariidae) in the complex bay-estuary of São Vicente, SP, Brazil. Biota Neotrop. 8(4): http:// www.biotaneotropica.org.br/v8n4/en/abstract?article+bn0 1108042008. 2008.

SILVEIRA, E.C. A pesca artesanal no contexto do desenvolvimento econômico versus sustentável. 2009. Dissertação apresentada ao Programa de Pós-Graduação em Desenvolvimento Regional- Mestrado e Doutorado, área de concentração em Tecnologia Ambiental, Universidade de Santa Cruz do Sul- UNISC, como requisito final para obtenção do título de Mestre em Desenvolvimento regional.

VAZOLLER, A.E. de M. Reprodução de peixes teleósteos: teoria e prática. Maringá, Editora Universidade Estadual de Maringá, 1996, 169p.

VERÍSSIMO, S. A. A Pesca na Amazônia. Rio de Janeiro: Livraria Clássica Alves \& Cia, 1970, 206 p.

WIDJAJA, W. P.; Abdulamir, A. S.; Saari, N. B.; Bakar, F. B. A.; Ishak. Z. B. Fatty acids profile of tropical bagridae catfish (Mystus nemurus) during storage. American Journal of Food Technology. v. 4, p. 90 - 95, 2009.

ZAVALA-CAMIN, L. A. Introdução aos Estudos Sobre Alimentação Natural Em Peixes. Maringá:EDUEM. 1996. 